\title{
Association of body mass index with ER, PR and 14-3-30 expression in tumor and stroma of type I and type II endometrial carcinoma
}

\author{
Joseph F. Peevey ${ }^{1}$, Brandon-Luke L. Seagle ${ }^{2}$, Kruti P. Maniar ${ }^{1}$ and J. Julie Kim ${ }^{3}$ \\ ${ }^{1}$ Department of Pathology, Northwestern University Feinberg School of Medicine, Chicago, IL, USA \\ ${ }^{2}$ Division of Gynecologic Oncology, Department of Obstetrics and Gynecology, Northwestern University Feinberg School of \\ Medicine, Chicago, IL, USA \\ ${ }^{3}$ Division of Reproductive Science in Medicine, Department of Obstetrics and Gynecology, Northwestern University Feinberg \\ School of Medicine, Chicago, IL, USA
}

Correspondence to: J. Julie Kim, email: j-kim4@northwestern.edu

Keywords: endometrial cancer, $P R, E R, 14-3-3$, obesity

Received: January 26, 2017 Accepted: April 06, $2017 \quad$ Published: April 18, 2017

Copyright: Peevey et al. This is an open-access article distributed under the terms of the Creative Commons Attribution License 3.0 (CC BY 3.0 ), which permits unrestricted use, distribution, and reproduction in any medium, provided the original author and source are credited.

\section{ABSTRACT}

Obesity is a prominent risk factor for endometrial cancer (EC) and can impede on surgical and hormonal treatments. Markers of EC, estrogen receptor (ER), progesterone receptor (PR), phospho(Ser473)-AKT (PAKT) and 14-3-3 sigma (14-3-3 $\sigma$ ) were measured in EC tissues in both the tumor and stroma and grouped by body mass index (BMI). Immunohistochemical scoring of 82 cases of Type 1 and Type II EC tissues revealed a significantly increased tumor expression of ER, PR and 14-3-3 $\sigma$ in women with Type I (BMI < 40) as compared to Type II (BMI < 30) EC. With higher BMI, only PR and 14-3-3 $\sigma$ in the tumor epithelium was significantly higher in Type I than Type II. In particular, Type I EC exhibited significantly increased levels of only PR from patients with BMI > 40 compared to BMI < 40. Type II EC showed increased expression of ER in the stroma only between high and low BMI. Analysis of the TCGA RNA-Seq mRNA expression of ER, PR, PIK3CA, PTEN and SFN (gene for 14-3-3 $\sigma$ ) confirmed increased PR expression in EC of obese women. In conclusion, ER, PR and 14-3-3 $\sigma$ are differentially regulated in Type I compared to Type II EC while PR is dysregulated in obese women with Type I EC. These findings have potential implications for efficacy of progestin treatment in obese women.

\section{INTRODUCTION}

Endometrial cancer (EC) is the most common gynecologic malignancy with an estimated 60,050 new cases and 10,470 deaths in the US in 2016 [1]. These numbers steadily increase each year. EC are traditionally classified as Type I or Type II based upon histology. Type I EC are most prevalent and exhibit frequent mutations in PTEN, members of the PI3K/AKT pathway, FGFR2, ARID1A, CTNNB1, PIK3CA, PIK3R1 and KRAS [2-4].

It remains unclear if tumor expression of estrogen receptor (ER) or progesterone receptor (PR) is independently associated with EC survival after adjusting for histologic type and tumor grade. While older studies suggested prognostic associations, a very recent analysis showed that knowing tumor ER or PR status did not improve prediction of survival $[5,6]$. Moreover, ER and PR levels are traditionally assessed in the tumor cells exclusively and not in the surrounding stromal cells, despite expression of ER and PR in the stroma. Given the important paracrine actions of estrogen and progesterone between the epithelial/tumor and stromal cells [7-11], analysis of the stroma would provide additional and potentially useful information.

Prolonged unopposed estrogen exposure and conditions such as obesity, polycystic ovarian syndrome, estrogen-only hormone replacement therapy (HRT), and prolonged tamoxifen use, increase the risk of developing Type I EC [12-14]. The association of obesity and EC incidence is significant [15]. While frequently attributed to the mitogenic influence of excess estrogen, little is known about the mechanisms underlying this association. A BMI of 42 increases the risk of developing EC by tenfold compared to normal weight [16]. Type II EC is less common and often presents at an advanced stage with poor prognosis leading to a disproportionate number 
of EC specific deaths. Type II EC include serous, clear cell, carcinosarcoma, and FIGO grade 3 endometrioid histologies, characterized by mutations in TP53, CHD4, and $F B X W 7$, among others [17, 18].

We previously reported that resistance to progestins can occur due to hyperactivation of AKT signaling in endometrial tumor cells. We also discovered a novel partner of PR, 14-3-3 $\sigma$, that is recruited with PR on chromatin and sensitizes EC cells to progestins [19]. $14-3-3 \sigma$ proteins are ubiquitously expressed regulators of various cellular functions, including proliferation, metabolism, and differentiation [20]. 14-3-3 $\sigma$ is frequently decreased or lost in human cancers including breast, liver, prostate, lung and ovarian cancer [21-25].

The goal of this study was to determine the expression pattern of ER, PR, pAKT and 14-3-3 $\sigma$ in EC tissues from obese and non-obese women. Levels in both epithelial and stromal cells of Type I and Type II EC tumors were assessed and compared in relation to BMI.

\section{RESULTS}

\section{Type I and Type 2 Endometrial cancer marker expression according to BMI}

Clinical data including BMI and final pathological diagnosis were documented for the 82 cases represented on the tissue microarray (TMA). Cases were grouped by Type I (Grade 1 and 2 endometrioid adenocarcinoma, $n=56$ ) and Type II (uterine serous, clear cell, carcinosarcoma, and grade 3 endometrioid adenocarcinoma, $n=26$ ). In addition, these data were separated by BMI to group the data into obese and non-obese BMI. For Type I EC, cases were grouped by BMI $>$ or $<40$. For Type II, BMI $>$ or $<30$ was used due to the low number of cases with BMI of $>40$. The frequency distribution of staining scores (0-3) was calculated and statistically analyzed. Representative images for marker staining with scores of 0 and 3 are shown in the tumor epithelium (Figure 1) and stroma (Figure 2). The percent frequency distribution was then plotted as contingency graphs. In obese cases, expression of PR and $14-3-3 \sigma$ in the tumor epithelium was significantly higher in Type I compared to Type II EC (Figure 3). In Type I EC, PR levels in the tumor epithelium were scored at $2(14 \%)$ or 3 (86\%) as opposed to Type II tumors which exhibited lower PR levels ( $43 \%$ at $0,21 \%$ at $1,21 \%$ at 2 , and $14 \%$ at 3$)$. For $14-3-3 \sigma, 86 \%$ of Type I stroma epithelium scored highly at 3 as opposed to $62 \%$ in Type II tumors. ER and pAKT levels did not differ statistically for frequency of score distribution between the two types of EC. In addition, no differences in staining were observed in the tumor stroma.

Comparison of Type I and Type II EC in nonobese women (BMI $<40$ or $<30$ respectively), revealed significant increase in levels of PR, ER and 14-3-3 $\sigma$ in the tumor epithelium in Type I EC (Figure 4). Levels of pAKT did not differ significantly in the tumor epithelium. In the stroma, despite positive staining, there was no significant difference in expression of PR, ER, pAKT or 14-3-3 $\sigma$ between Type I and Type II. Interestingly, in our cohort of cases, the Type I tumors with BMI between 40 and 30 exhibited staining levels similar to cases of BMI $<30$ (data not shown) and thus these cases were combined in one group (BMI < 40).

\section{Endometrial cancer marker expression in Type I tumors comparing obese and non-obese cases}

Levels of markers were compared in Type I EC in BMI $>$ vs $<40$. There were a total of 14 Type I cases of BMI $>40$ and 43 cases of BMI $<40$. Analysis of the percent frequency distribution of scores showed a significant difference in only the PR levels in the tumor epithelium while other markers in the tumor epithelium as well as the stroma did not show significant differences in staining (Figure 5). PR in the tumors of BMI $>40$ cases scored higher than BMI $<40$ cases.

Type II tumors were grouped as BMI $>$ or $<30$ as only 1 case was from a woman with a BMI $>40$. In total, 14 Type II cases of BMI $>30$ and 12 cases $\mathrm{BMI}<30$ were analyzed. The group with BMI $>30$ exhibited increased staining of ER in the stroma compared to nonobese women (Figure 6). None of the other markers were significantly different in the tumor epithelium or stroma in the two groups.

\section{Endometrial cancer marker expression from the cancer genome atlas (TCGA) by BMI}

In order to determine whether the EC markers studied here differed in obese and non-obese women at the mRNA level, we explored the existing TCGA database that was generated in endometrial carcinoma [3]. We did a preliminary query of 6 genes that were of interest to us (Table 1) and grouped the transcriptomic data by BMI [morbidly obese $(\mathrm{BMI}>40)$ or non-obese $(\mathrm{BMI}<30)$ ] for only endometrioid cases (Type 1). There were 37 cases of non-obese women and 24 women of morbidly obese women available that fit these criteria. Preliminary analysis of 6 genes showed an increase of PR expression in morbidly obese women by 4 fold. ESR1, ESR2, and PIK3CA expression were not significantly different, PTEN was slightly elevated (1.25 fold, $p=0.04)$ and interestingly the gene for $14-3-3 \sigma$, SFN was decreased $(0.526, p=0.054)$ (Table 1$)$. Correlation tests showed analogous directional relationships of tumor PGR, PTEN and SFN mRNA expression across the range of observed BMI values (Table 2).

\section{DISCUSSION}

This study revealed that among the EC markers studied, PR and 14-3-3 $\sigma$ protein levels were significantly 
Table 1: Differential mRNA expression between primary tumors from women with BMI $\geq 40$ (morbidly obese) versus BMI $\leq 30$ (non-obese) from TCGA database

\begin{tabular}{lllcc}
\hline Gene & Exp - BMI $<\mathbf{3 0}(n=\mathbf{3 7})$ & Exp - BMI $>$ 40 $(n=\mathbf{2 4})$ & Fold Change & $\boldsymbol{P}$ \\
\hline ESR1 & $5661(2097-9880)$ & $7317(2895-11125)$ & 1.29 & 0.775 \\
ESR2 & $13(8-20)$ & $14(10-21)$ & 1.09 & 0.543 \\
PGR & $989(231-3030)$ & $4469(918-8179)$ & 4.52 & 0.055 \\
PIK3CA & $251(195-354)$ & $224(160-336)$ & 0.894 & 0.294 \\
PTEN & $1304(916-1624)$ & $1632(1381-1993)$ & 1.25 & 0.043 \\
SFN & $3170(1877-5652)$ & $1668(1230-4546)$ & 0.526 & 0.054 \\
\hline
\end{tabular}

Exp is mRNA expression from primary tumor RNA Sequencing and is reported as median (IQR). P is from Mann-Whitney $U$ test.

higher in Type I versus Type II tumors, while only PR protein level expression was higher in Type I tumors when comparing tumors from women of BMI $>40$ or BMI $<40$. Analysis of the TCGA database confirmed that PR mRNA was higher in tumors from cases of BMI $>40$

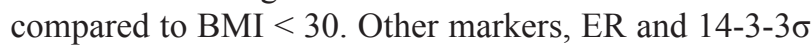

were significantly different only when comparing Type I versus Type II EC from patients with BMI $<40$ or $<30$ respectively. The differential regulation of PR between Type I and Type II cancers as well as within Type I cancers depending on BMI, supports the influential role of PR in this cancer. Recently, a group analyzed the TCGA database

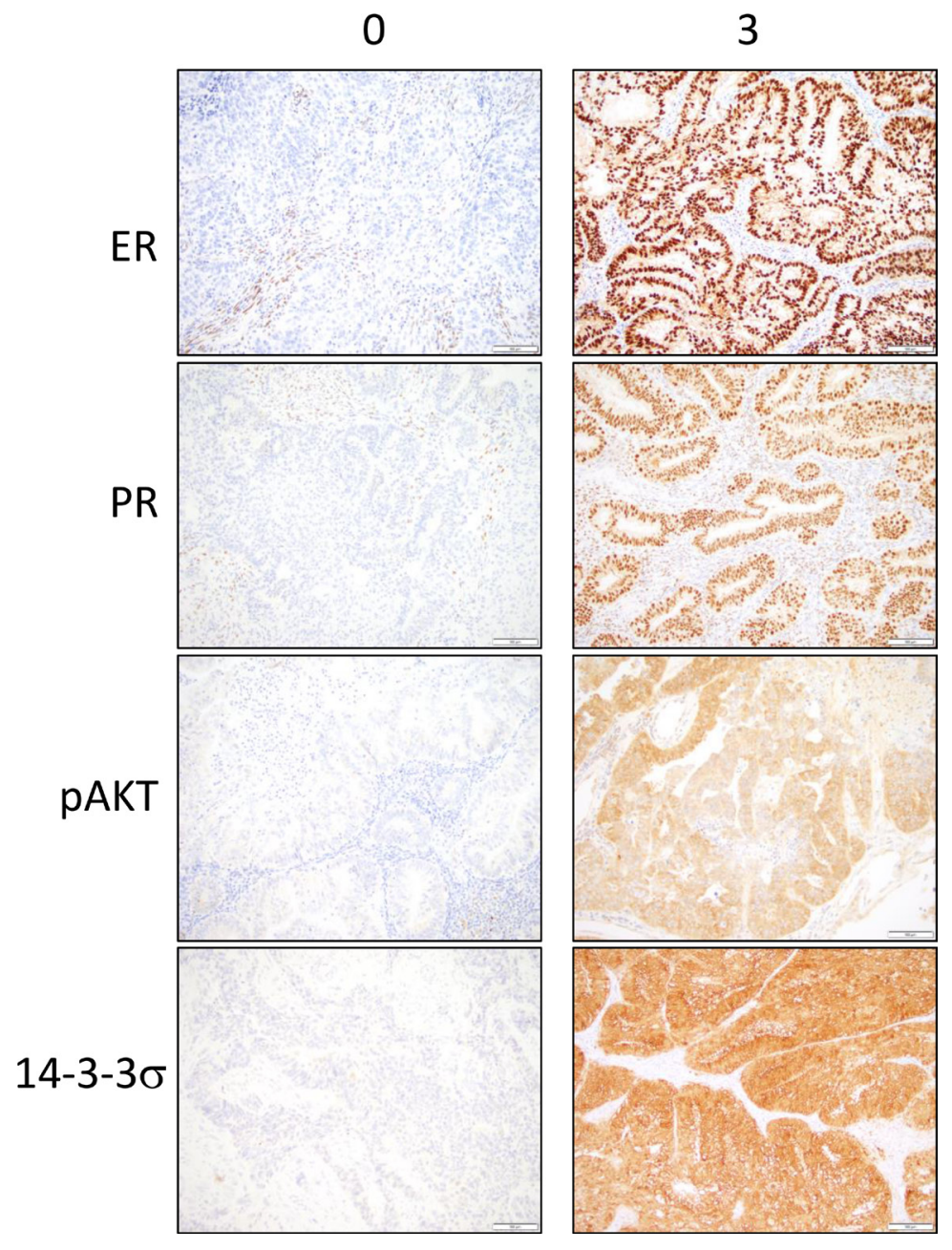

Figure 1: Immunohistochemical stainings for ER, PR, pAKT and 14-3-3 $\sigma$ in the tumor epithelium are observed in tumor cores from the endometrial cancer tissue microarray. Representative sections of low expression $(0)$ and high expression (3) are shown. Brown color represents positive staining. 
Table 2: Correlation test as BMI and mRNA expression are continuous variables

\begin{tabular}{ccc}
\hline Gene & Spearman's rho & $\boldsymbol{P}$ \\
\hline ESR1 & 0.051 & 0.623 \\
ESR2 & 0.121 & 0.246 \\
PGR & 0.240 & 0.020 \\
PIK3CA & -0.164 & 0.114 \\
PTEN & 0.204 & 0.048 \\
SFN & -0.177 & 0.088 \\
\hline
\end{tabular}

for EC to evaluate the differences in gene expression of obese and non-obese women with EC [26]. They identified 181 genes that were significantly up- or down-regulated with increasing BMI and among the genes PR expression was increased. Our data support the upregulation of PR both at the mRNA and protein levels. We were also able to stratify the expression of markers depending on BMI in each Type of EC as well as distinguish staining in the tumor epithelium and stroma. Of note was the significant increase in ER staining in the stroma of Type II EC in women of BMI $>30$. While Type II cancers have not been considered as hormone-dependent, the role of hormones
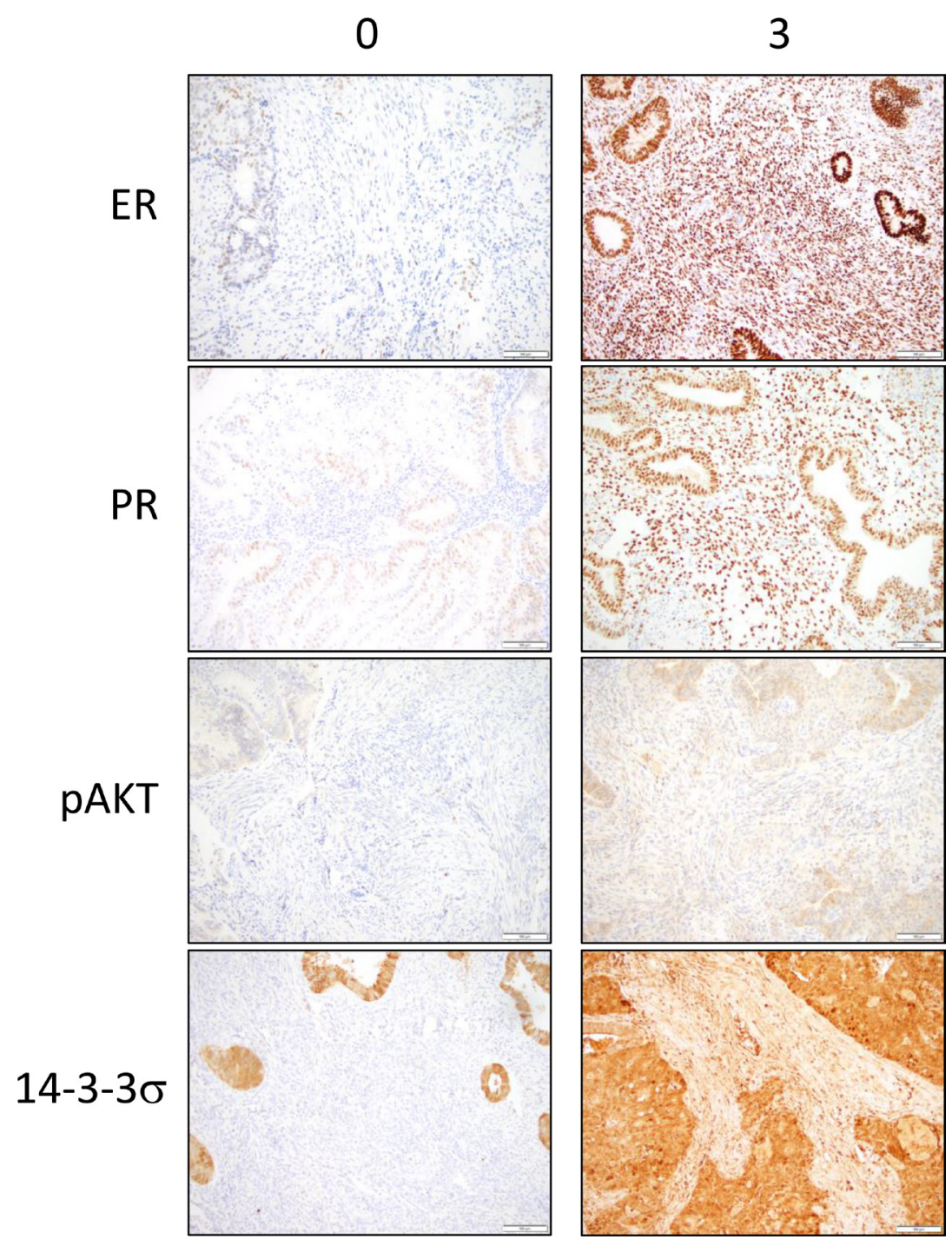

Figure 2: Immunohistochemical stainings for ER, PR, pAKT and 14-3-3 $\sigma$ in the stroma are observed in tumor cores from the endometrial cancer tissue microarray. Representative sections of low expression (0) and high expression (3) are shown. Brown color represents positive staining. 


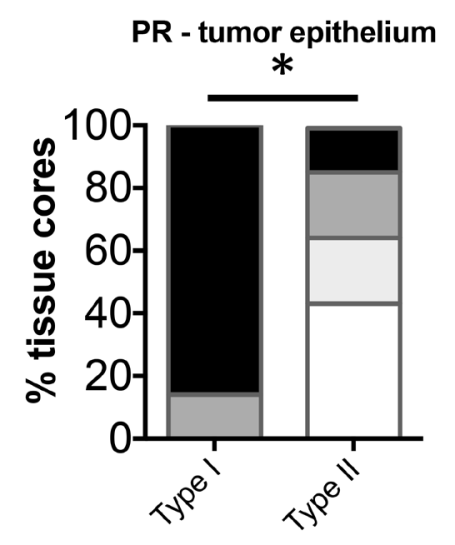

ER - tumor epithelium

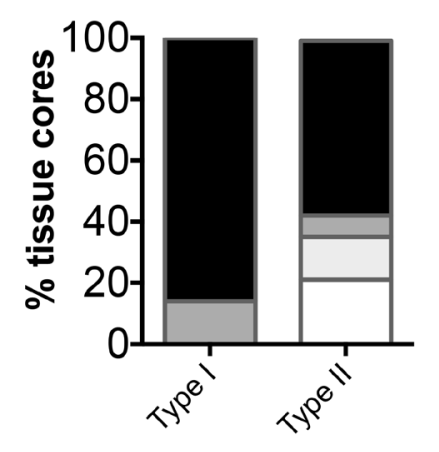

pAKT- tumor epithelium

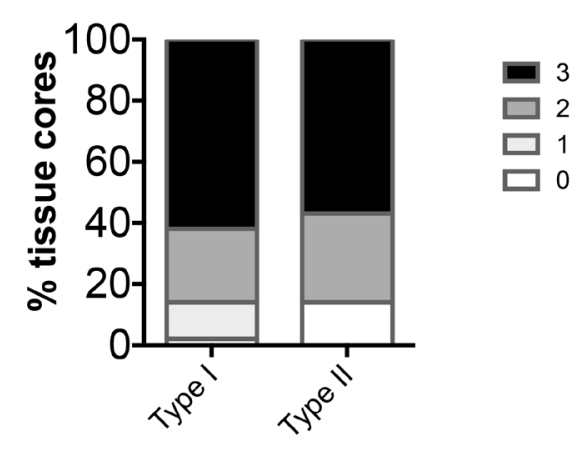

14-3-3 - tumor epithelium

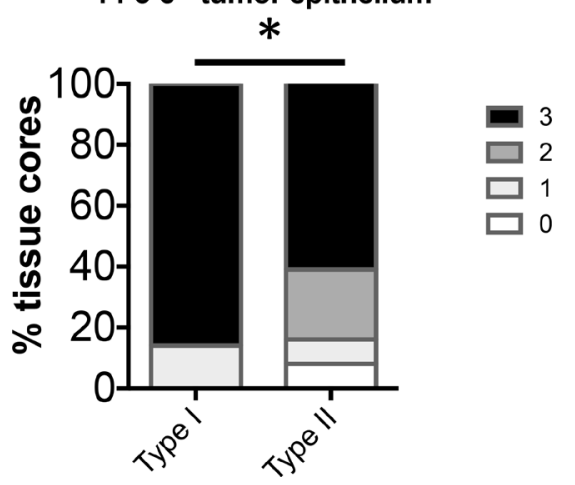

PR - stroma

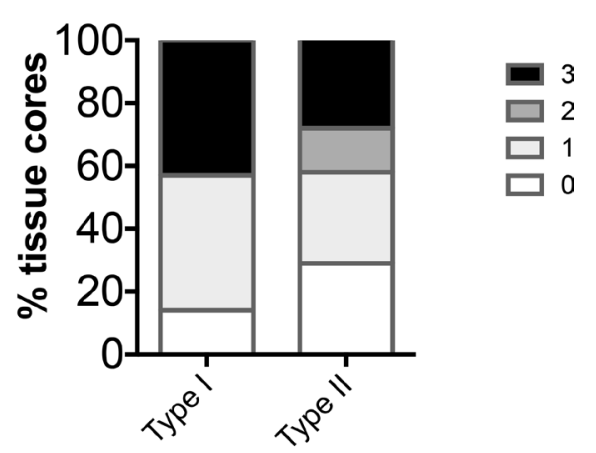

ER - stroma
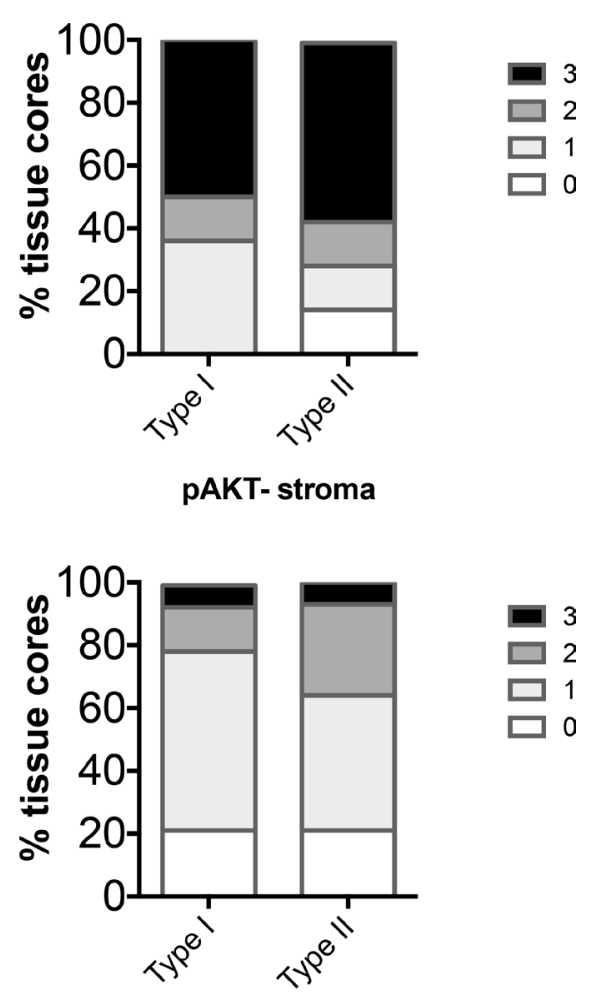

14-3-3 - stroma

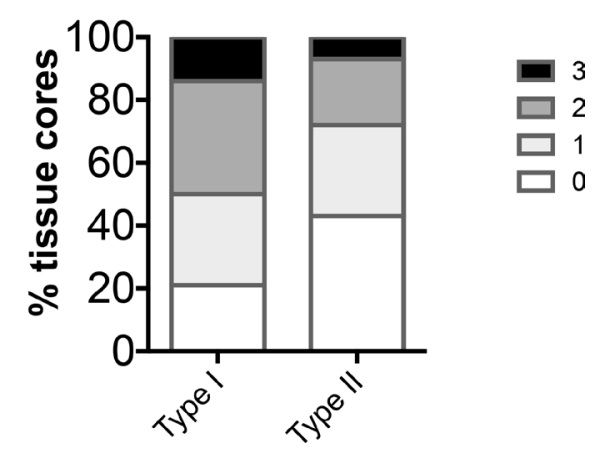

Figure 3: Comparison of distribution of intensity scores between Type I (BMI > 40) and Type II (BMI $\geq 30$ ) tumors from obese women. The intensity of staining in the tumor epithelium and stroma in each of the tissue cores was scored numerically as 0 (negative), 1 (weak), 2 (moderate), or 3 (strong). Statistically significant differences between Type I and Type II tissues were evaluated using the Mann-Whitney $U$ test $(* P<0.05)$. 
cannot entirely be ruled out. Analysis of sex hormone levels including estradiol, progesterone, testosterone, FSH and LH as well as levels of ER and PR in the tumors were measured in 187 women with EC [27]. Hormone

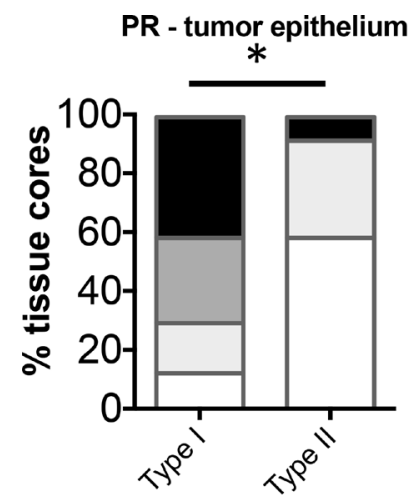

ER - tumor epithelium
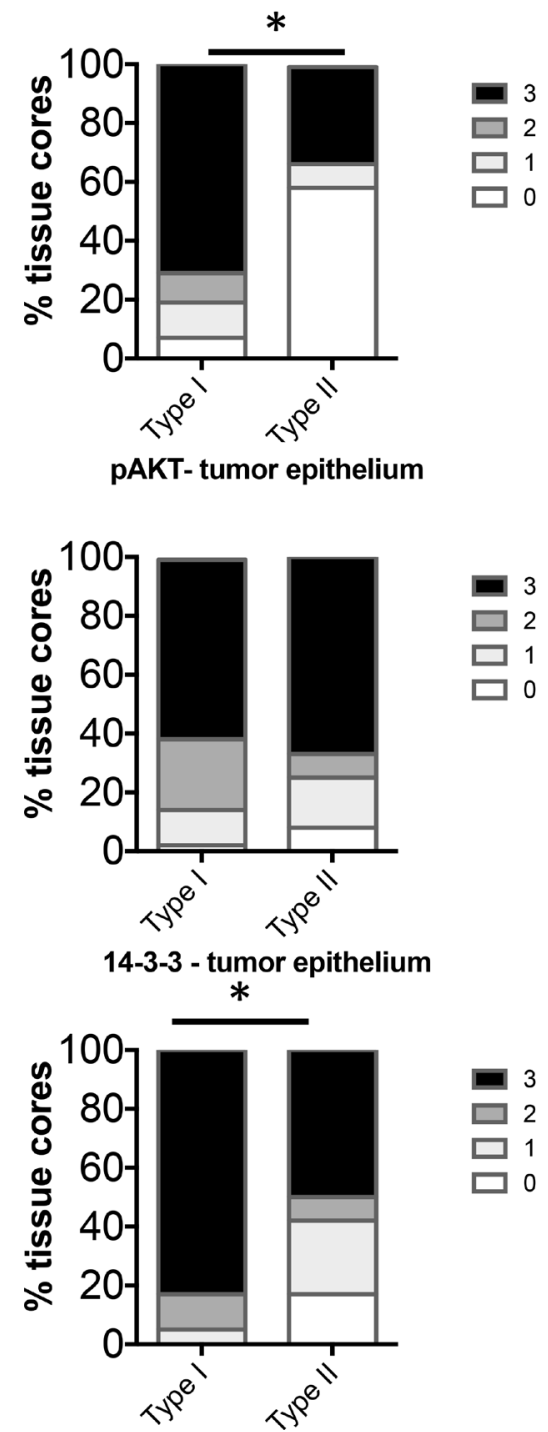

levels were similar between the subtypes of EC regardless of menopausal status, and most of the Type I and II ECs were positive for ER and PR. Thus, the potential regulation of stromal ER in Type II EC in obese women is

PR - stroma

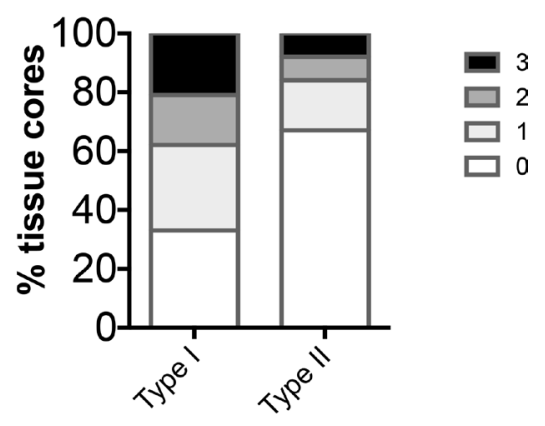

ER - stroma
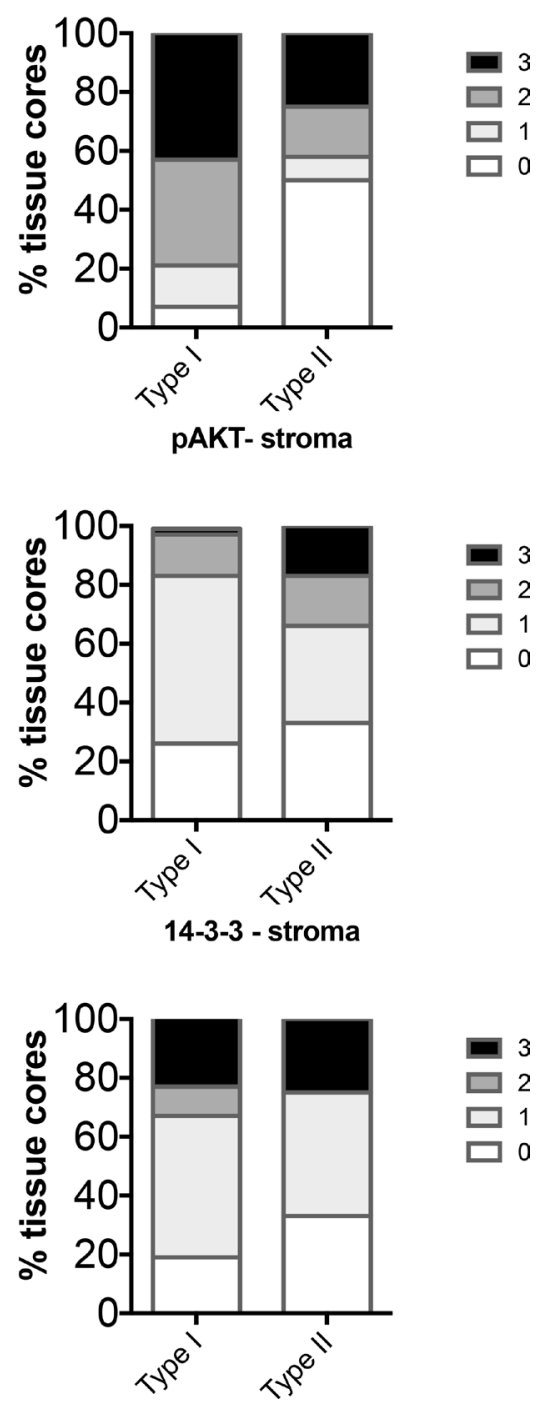

Figure 4: Comparison of distribution of intensity scores between Type I (BMI < 40) and Type II (BMI < 30) tumors from non-obese women. The intensity of staining in the tumor epithelium and stroma in each of the tissue cores was scored numerically as 0 (negative), 1 (weak), 2 (moderate), or 3 (strong). Statistically significant differences between Type I and Type II tissues were evaluated using the Mann-Whitney $U$ test $(* P<0.05)$. 
of interest and may implicate effects of the inflammatory microenvironment caused by obesity.

Studies show that up to $50 \%$ of EC cases treated with progestins fail to show a complete response [28].

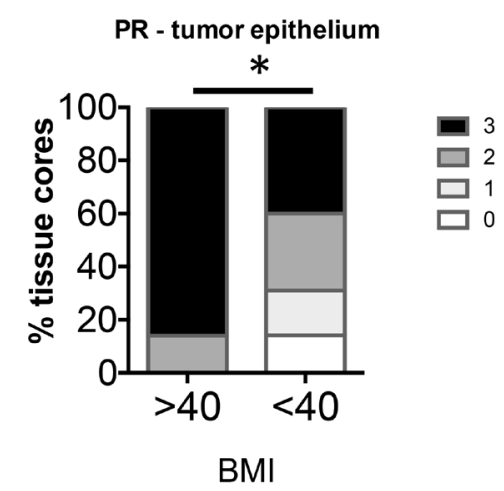

ER - tumor epithelium

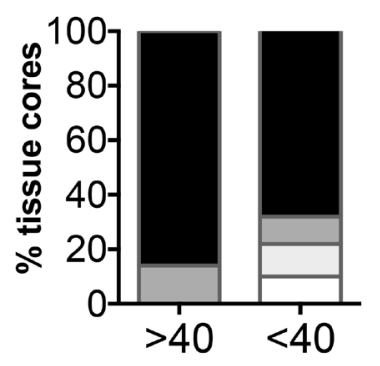

BMI

PAKT- tumor epithelium

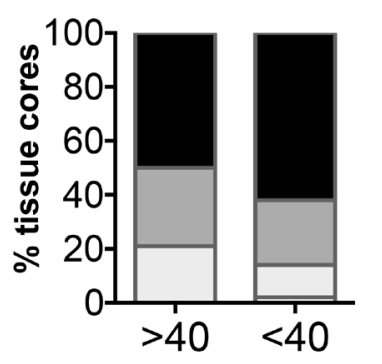

BMI

14-3-3 - tumor epithelium

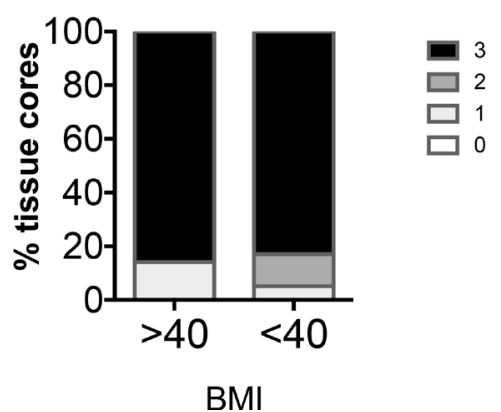

Additionally, with advancing disease, the sensitivity to progestins decreases $[29,30]$. Methylation of the PR promoter has been demonstrated in EC [31] resulting in decreased levels of PR. EC cells that were negative for
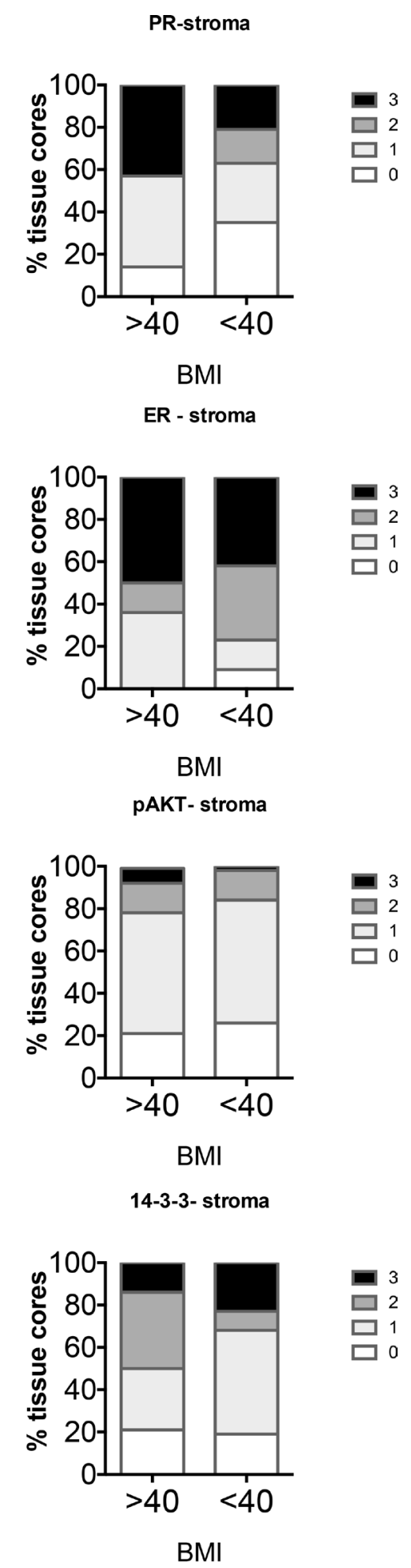

Figure 5: Comparison of distribution of intensity scores of Type I tumors from women with BMI $>$ or $<40$. The intensity of staining in the tumor epithelium and stroma in each of the tissue cores was scored numerically as 0 (negative), 1 (weak), 2 (moderate), or 3 (strong). Statistically significant differences between tissues from BMI $>$ or $<40$ were evaluated using the Mann-Whitney $U$ test $(* P<0.05)$. 
PR can gain PR expression using epigenetic modulators [32]. Post-translational modifications of PR including phosphorylation, sumoylation, ubiquitination and acetylation can alter protein stability, localization and function [33]. Hyperactivated signaling pathways can

PR - tumor epithelium

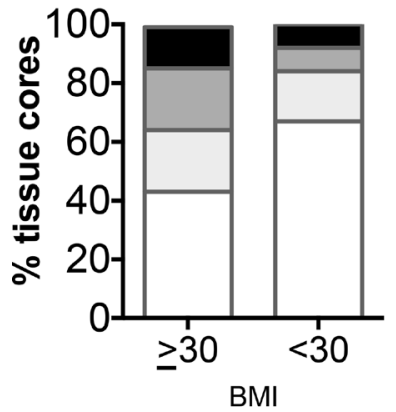

ER - tumor epithelium

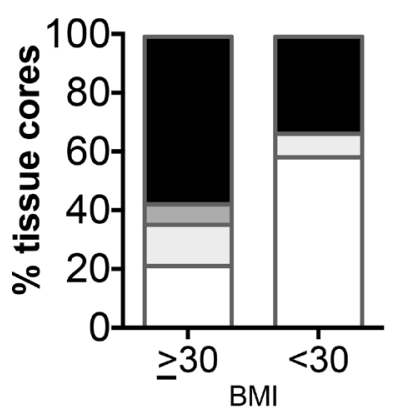

pAKT- tumor epithelium

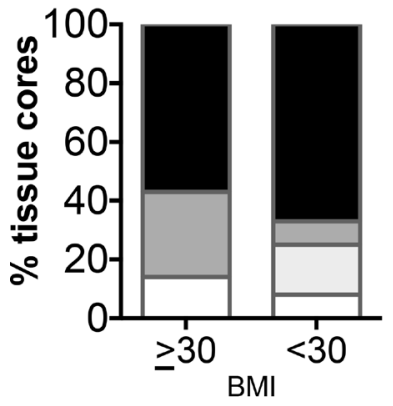

14-3-3 - tumor epithelium

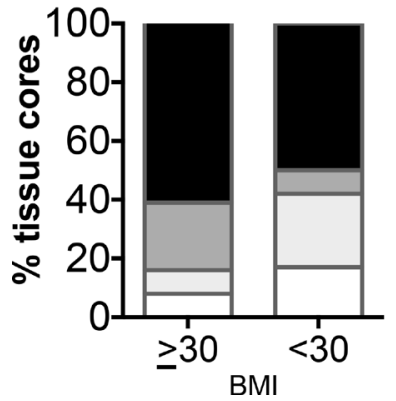

promote post-translational modifications of PR as well as regulate important coregulators that influence PR action at the chromatin $[19,34]$. Recently, we reported that hyperactivated AKT pathway in EC alters PR action and significantly affects the proteins that co-precipitate with
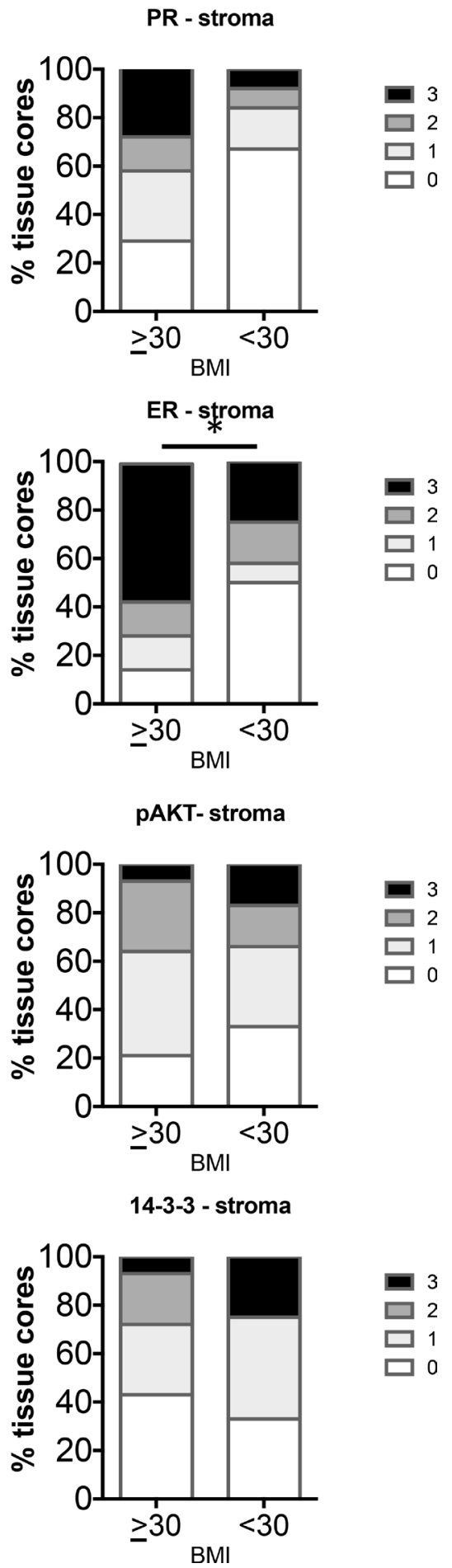

Figure 6: Comparison of distribution of intensity scores of Type II tumors from women with BMI $\geq$ or $<30$. The intensity of staining in the tumor epithelium and stroma in each of the tissue cores was scored numerically as 0 (negative), 1 (weak), 2 (moderate), or 3 (strong). Statistically significant differences between tissues from BMI $\geq$ or $<30$ were evaluated using the Mann-Whitney $U$ test $(* P<0.05)$. 
PR at the chromatin [19]. We identified the 14-3-3 family of proteins to be recruited with PR upon inhibition of AKT and specifically, 14-3-3 $\sigma$ increased PR activity on a subset of genes. The higher expression of 14-3-3 $\sigma$ in Type I EC regardless of BMI compared to Type II cases suggests that 14-3-3 $\sigma$ could influence PR action preferentially in Type I.

Response rates to progestins for early EC vary among studies, which are usually limited to small case numbers. Upon review of published studies, response rates to progestins range from approximately $40 \%$ to $85 \%$ [28, 35-40]. Two studies reported that obese patients have lower response rates to progestins than non-obese patients $[35,41]$. The higher PR expression observed in Type I EC with $\mathrm{BMI}>40$ in our study seemed counterintuitive to this, as higher levels of receptor are usually associated with increased response to the hormone. However, we know from our studies and others that there are numerous factors which influence PR transcriptional function and thus, it would be necessary to study this in the obese setting. An increase in hormone receptor levels could also be indicative of inactive receptors since active receptors are usually ubiquitinated and turned over rapidly [42, 43]. Despite the lack of statistical difference in 14-3-3 $\sigma$ at the protein level, the TCGA data showed lower SFN as well as higher PR expression in cases of BMI $>40$, compared to $\mathrm{BMI}<30$. If indeed $14-3-3 \sigma$ serves as an important regulator of $\mathrm{PR}$ transcriptional function in primary human tumors as we see for EC cell lines [19], this gene could be used in addition to PR to predict PR activity. Although earlier studies have associated ER and PR with a favorable response to progestins, PR positive tumors do not always respond [29]. Moreover, some ER/PR-negative tumors have exhibited response to progestins. Reasons for this are numerous [44] and require an in depth analysis especially in the context of obesity. Obesity is considered to be a disease of inflammation [45] and could influence PR action at the level of post-translational modifications, protein stability, localization and recruitment of essential coregulators, as well as its microenvironment. Additional studies are warranted to determine the influence of obesity on progestin response for EC.

Obesity has become a major health concern in the United States with 1 in 3 adults considered to be obese and about one-third of children and adolescents ages 6 to 19 to be overweight or obese [46, 47]. One study reported that obesity at a younger age increases risk for EC even if weight is lost in adulthood [48]. The prevalence of obesity and the rise in incidence of EC warrants better measures for prevention as well as early treatment. Our data raise consideration that background stromal expression of hormone receptors and their associated markers including 14-3-3 $\sigma$ may be considered in the development of predictive models of response to hormone treatment. Additionally, patient BMI should be investigated as a confounder or effect modifier of tumor epithelial and stromal marker expression as a predictor of response to hormonal treatment.

\section{MATERIALS AND METHODS}

\section{Human endometrial cancer tissues}

Uterine tumors were obtained from women who provided written informed consent prior to surgery. This study was approved by the Institutional Review Board of Northwestern University.

\section{Tissue microarray}

A TMA was created by the Human Pathology Core at the Robert $\mathrm{H}$ Lurie Comprehensive Cancer Center at Northwestern University. The TMA consisted of a $7 \times 14$ grid of $1.5 \mathrm{~mm}$ tissue cores. The grid included 89 randomly positioned EC tissues as well as 4 control tissues of normal endometrium. Of the 89 tumors, 7 cases were eliminated from analyses as 2 cases were leiomyosarcoma and 5 were atypical hyperplasia.

\section{Immunohistochemistry}

Immunohistochemistry was performed for the following proteins: ER (Clone SP1, Thermo Scientific Catalog \# RM-91), PR (Clone PgR 636, Dako Catalog \# M3569), p(Ser473)-AKT (Cell Signaling, Catalog \#

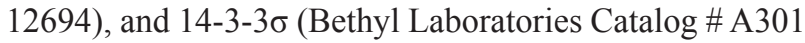
-648A). All Immunohistochemistry was performed at the Pathology Core Facility of the Robert H. Lurie Comprehensive Cancer Center of Northwestern University. Antibodies were tested on negative and positive control tissues provided by the Core Facility. Semiquantitative immunoreactivity for all markers was scored by a pathologist. Immunostains were scored as the percent of positively stained cells: [(0) absent; (1) $<10 \%$; (2) $11-50 \%$; (3) $>50 \%]$.

\section{The cancer genome atlas primary tumor mRNA expression by body mass index}

Publicly available EC clinical and primary tumor mRNA gene expression datasets from TCGA were downloaded from cBioPortal [3, 49, 50]. Public data use for research was per TCGA policies [51]. Only tumors with endometrioid histology were analyzed. A total of 94 endometrioid tumors had data for mRNA expression and BMI. Primary tumor mRNA expression was compared between non-obese (BMI $\left.<30 \mathrm{~kg} / \mathrm{m}^{2}, n=37\right)$ and morbidly obese (BMI $\geq 40 \mathrm{~kg} / \mathrm{m}^{2}, n=24$ ) women using the Mann-Whitney $U$ test. The correlation of mRNA expression and BMI was tested with Spearman's rank correlation test.

\section{Statistical analyses}

The immunostaining score frequency distribution of TMAs was compared with the Mann-Whitney $U$ test. 
Tumor mRNA expression from the TCGA endometrioid EC cohort were compared using the Mann-Whitney $U$ test. Groupings for comparisons are indicated in Results. Statistical tests were performed with $\mathrm{R}$ version 3.3.1 (2016-06-21) [52].

\section{Abbreviations}

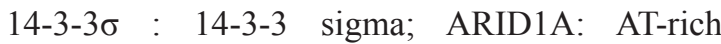
interaction domain 1A; BMI: body mass index; CHD4: chromodomain helicase DNA binding protein 4; CTNNB1: catenin beta 1; EC: endometrial cancer; ER: estrogen receptor; FBXW7: F-box and WD repeat domain containing 7; FGFR2: fibroblast growth factor receptor 2; FSH: follicle stimulating hormone; KRAS: KRAS protooncogene, GTPase; LH: luteinizing hormone; pAKT: phospho(Ser473)-AKT; PIK3CA: phosphatidylinositol4,5-bisphosphate 3-kinase catalytic subunit alpha; PIK3R1: phosphoinositide-3-kinase regulatory subunit 1; PR: progesterone receptor; PTEN: phosphatase and tensin

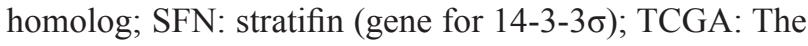
Cancer Genome Atlas; TMA: Tissue microarray; TP53: tumor protein p53.

\section{Authors' contributions}

Conceptualization: Formulation of overarching research goals and aims. JKim. Methodology: Development or design of methodology; creation of models. JKim; Validation: Verification, whether as a part of the activity or separate, of the overall replication/ reproducibility of results/experiments and other research outputs. JPeevey, BSeagle, KManiar, JKim; Formal analysis: Application of statistical, mathematical, computational, or other formal techniques to analyze or synthesize study data. JPeevey, BSeagle, KManiar, JKim; Investigation: Research and investigation process, specifically performing the experiments, or data/evidence collection. JPeevey, BSeagle, KManiar; 6. Resources: Provision of study materials, reagents, materials, patients, laboratory samples, animals, instrumentation, computing resources, or other analysis tools. BSeagle, JKim; Data curation: Management activities to annotate (produce metadata), scrub data and maintain research data (including software code, where it is necessary for interpreting the data itself) for initial use and later re-use. JKim; Writing - original draft: Preparation, creation and/or presentation of the published work, specifically writing the initial draft (including substantive translation). JPeevey, BSeagle, JKim; Writing - review and editing: Preparation, creation and/or presentation of the published work by those from the original research group, specifically critical review, commentary or revision - including pre- or post-publication stages. JPeevey, BSeagle, KManiar, JKim; Visualization: Preparation, creation and/or presentation of the published work, specifically visualization/data presentation. JPeevey, BSeagle, KManiar, JKim; Supervision: Oversight and leadership responsibility for the research activity planning and execution, including mentorship external to the core team. KManiar, JKim; Project administration: Management and coordination responsibility for the research activity planning and execution. JKim; Funding acquisition: Acquisition of the financial support for the project leading to this publication. JKim.

\section{ACKNOWLEDGMENTS}

We would like to acknowledge the Human Pathology Core at Robert Lurie Comprehensive Cancer Center for creating the TMAs from the endometrial cancer tissues that were collected by our lab.

\section{CONFLICTS OF INTEREST}

No potential conflicts of interest were disclosed by all authors.

\section{FUNDING}

National Institute of Health, National Cancer Institute RO1CA155513.

\section{REFERENCES}

1. Siegel RL, Miller KD, Jemal A. Cancer statistics, 2016. CA Cancer J Clin. 2016; 66:7-30.

2. Byron SA, Gartside M, Powell MA, Wellens CL, Gao F, Mutch DG, Goodfellow PJ, Pollock PM. FGFR2 point mutations in 466 endometrioid endometrial tumors: relationship with MSI, KRAS, PIK3CA, CTNNB1 mutations and clinicopathological features. PLoS One. 2012; 7:e30801.

3. Cancer Genome Atlas Research Network, Kandoth C, Schultz N, Cherniack AD, Akbani R, Liu Y, Shen H, Robertson AG, Pashtan I, Shen R, Benz CC, Yau C, Laird PW, et al. Integrated genomic characterization of endometrial carcinoma. Nature. 2013; 497:67-73.

4. McConechy MK, Ding J, Cheang MC, Wiegand KC, Senz J, Tone AA, Yang W, Prentice LM, Tse K, Zeng T, McDonald H, Schmidt AP, Mutch DG, et al. Use of mutation profiles to refine the classification of endometrial carcinomas. J Pathol. 2012; 228:20-30.

5. Busch EL, Crous-Bou M, Prescott J, Chen MM, Downing MJ, Rosner B, Mutter GL, De Vivo I. Endometrial cancer risk factors, hormone receptors, and mortality prediction. Cancer Epidemiol Biomarkers Prev. 2017.

6. Chambers JT, MacLusky N, Eisenfield A, Kohorn EI, Lawrence R, Schwartz PE. Estrogen and progestin receptor levels as prognosticators for survival in endometrial cancer. Gynecol Oncol. 1988; 31:65-81. 
7. Kim TH, Yu Y, Luo L, Lydon JP, Jeong JW, Kim JJ. Activated AKT pathway promotes establishment of endometriosis. Endocrinology. 2014; 155:1921-1930.

8. Pawar S, Laws MJ, Bagchi IC, Bagchi MK. Uterine Epithelial Estrogen Receptor-alpha Controls Decidualization via a Paracrine Mechanism. Mol Endocrinol. 2015; 29:1362-1374.

9. Ren CE, Zhu X, Li J, Lyle C, Dowdy S, Podratz KC, Byck D, Chen HB, Jiang SW. Microarray analysis on gene regulation by estrogen, progesterone and tamoxifen in human endometrial stromal cells. Int J Mol Sci. 2015; 16:5864-5885.

10. Li Q, Kannan A, DeMayo FJ, Lydon JP, Cooke PS, Yamagishi H, Srivastava D, Bagchi MK, Bagchi IC. The antiproliferative action of progesterone in uterine epithelium is mediated by Hand2. Science. 2011; 331:912-916.

11. Pineda MJ, Lu Z, Cao D, Kim JJ. Influence of CancerAssociated Endometrial Stromal Cells on Hormone-Driven Endometrial Tumor Growth. Horm Cancer. 2015; 6:131-141.

12. Creasman WT. Endometrial cancer: incidence, prognostic factors, diagnosis, and treatment. Semin Oncol. 1997; 24:S1-140-S141-150.

13. Munstedt K, Grant P, Woenckhaus J, Roth G, Tinneberg HR. Cancer of the endometrium: current aspects of diagnostics and treatment. World J Surg Oncol. 2004; 2:24.

14. Sherman ME. Theories of endometrial carcinogenesis: a multidisciplinary approach. Mod Pathol. 2000; 13:295-308.

15. Mackintosh ML, Crosbie EJ. Obesity-driven endometrial cancer: is weight loss the answer? BJOG. 2013; 120:791-794.

16. Crosbie EJ, Zwahlen $M$, Kitchener HC, Egger $M$, Renehan AG. Body mass index, hormone replacement therapy, and endometrial cancer risk: a meta-analysis. Cancer Epidemiol Biomarkers Prev. 2010; 19:3119-3130.

17. Kuhn E, Wu RC, Guan B, Wu G, Zhang J, Wang Y, Song L, Yuan X, Wei L, Roden RB, Kuo KT, Nakayama K, Clarke B, et al. Identification of molecular pathway aberrations in uterine serous carcinoma by genome-wide analyses. J Natl Cancer Inst. 2012; 104:1503-1513.

18. Le Gallo M, O'Hara AJ, Rudd ML, Urick ME, Hansen NF, O’Neil NJ, Price JC, Zhang S, England BM, Godwin AK, Sgroi DC, Hieter P, Mullikin JC, et al, and NIH Intramural Sequencing Center (NISC) Comparative Sequencing Program. Exome sequencing of serous endometrial tumors identifies recurrent somatic mutations in chromatinremodeling and ubiquitin ligase complex genes. Nat Genet. 2012; 44:1310-1315.

19. Lee, II, Maniar K, Lydon JP, Kim JJ. Akt regulates progesterone receptor B-dependent transcription and angiogenesis in endometrial cancer cells. Oncogene. 2016.

20. Aitken A. 14-3-3 proteins: a historic overview. Semin Cancer Biol. 2006; 16:162-172.

21. Akahira J, Sugihashi Y, Suzuki T, Ito K, Niikura H, Moriya T, Nitta M, Okamura H, Inoue S, Sasano H, Okamura K, Yaegashi N. Decreased expression of 143-3 sigma is associated with advanced disease in human epithelial ovarian cancer: its correlation with aberrant DNA methylation. Clin Cancer Res. 2004; 10:2687-2693.

22. Cheng L, Pan CX, Zhang JT, Zhang S, Kinch MS, Li L, Baldridge LA, Wade C, Hu Z, Koch MO, Ulbright TM, Eble JN. Loss of 14-3-3sigma in prostate cancer and its precursors. Clin Cancer Res. 2004; 10:3064-3068.

23. Kuroda Y, Aishima S, Taketomi A, Nishihara Y, Iguchi T, Taguchi K, Maehara Y, Tsuneyoshi M. 14-3-3sigma negatively regulates the cell cycle, and its downregulation is associated with poor outcome in intrahepatic cholangiocarcinoma. Hum Pathol. 2007; 38:1014-1022.

24. Suzuki H, Itoh F, Toyota M, Kikuchi T, Kakiuchi H, Imai K. Inactivation of the 14-3-3 sigma gene is associated with 5' $\mathrm{CpG}$ island hypermethylation in human cancers. Cancer Res. 2000; 60:4353-4357.

25. Umbricht CB, Evron E, Gabrielson E, Ferguson A, Marks J, Sukumar S. Hypermethylation of 14-3-3 sigma (stratifin) is an early event in breast cancer. Oncogene. 2001; 20:3348-3353.

26. Roque DR, Makowski L, Chen TH, Rashid N, Hayes DN, Bae-Jump V. Association between differential gene expression and body mass index among endometrial cancers from The Cancer Genome Atlas Project. Gynecol Oncol. 2016; 142:317-322.

27. Wan J, Gao Y, Zeng K, Yin Y, Zhao M, Wei J, Chen Q. The levels of the sex hormones are not different between type 1 and type 2 endometrial cancer. Sci Rep. 2016; 6:39744.

28. Chiva L, Lapuente F, Gonzalez-Cortijo L, Carballo N, Garcia JF, Rojo A, Gonzalez-Martin A. Sparing fertility in young patients with endometrial cancer. Gynecol Oncol. 2008; 111:S101-104.

29. Thigpen JT, Brady MF, Alvarez RD, Adelson MD, Homesley HD, Manetta A, Soper JT, Given FT. Oral medroxyprogesterone acetate in the treatment of advanced or recurrent endometrial carcinoma: a dose-response study by the Gynecologic Oncology Group. J Clin Oncol. 1999; 17:1736-1744.

30. Carlson MJ, Thiel KW, Leslie KK. Past, present, and future of hormonal therapy in recurrent endometrial cancer. Int $\mathrm{J}$ Womens Health. 2014; 6:429-435.

31. Sasaki M, Dharia A, Oh BR, Tanaka Y, Fujimoto S, Dahiya R. Progesterone receptor B gene inactivation and $\mathrm{CpG}$ hypermethylation in human uterine endometrial cancer. Cancer Res. 2001; 61:97-102.

32. Yang S, Jia Y, Liu X, Winters C, Wang X, Zhang Y, Devor EJ, Hovey AM, Reyes HD, Xiao X, Xu Y, Dai D, Meng X, et al. Systematic dissection of the mechanisms underlying progesterone receptor downregulation in endometrial cancer. Oncotarget. 2014; 5:9783-9797. doi: 10.18632/oncotarget.2392.

33. Abdel-Hafiz HA, Horwitz KB. Post-translational modifications of the progesterone receptors. J Steroid Biochem Mol Biol. 2014; 140:80-89.

34. Proietti CJ, Izzo F, Diaz Flaque MC, Cordo Russo R, Venturutti L, Mercogliano MF, De Martino M, Pineda V, 
Munoz S, Guzman P, Roa JC, Schillaci R, Elizalde PV. Heregulin Co-opts PR Transcriptional Action Via Stat3 Role As a Coregulator to Drive Cancer Growth. Mol Endocrinol. 2015; 29:1468-1485.

35. Chen M, Jin Y, Li Y, Bi Y, Shan Y, Pan L. Oncologic and reproductive outcomes after fertility-sparing management with oral progestin for women with complex endometrial hyperplasia and endometrial cancer. Int J Gynaecol Obstet. 2016; 132:34-38.

36. Falcone F, Laurelli G, Losito S, Di Napoli M, Granata V, Greggi S. Fertility preserving treatment with hysteroscopic resection followed by progestin therapy in young women with early endometrial cancer. J Gynecol Oncol. 2017; 28:e2.

37. Kalogiannidis I, Agorastos T. Conservative management of young patients with endometrial highly-differentiated adenocarcinoma. J Obstet Gynaecol. 2011; 31:13-17.

38. Koskas M, Azria E, Walker F, Luton D, Madelenat P, Yazbeck C. Progestin treatment of atypical hyperplasia and well-differentiated adenocarcinoma of the endometrium to preserve fertility. Anticancer Res. 2012; 32:1037-1043.

39. Zhou R, Yang Y, Lu Q, Wang J, Miao Y, Wang S, Wang Z, Zhao C, Wei L. Prognostic factors of oncological and reproductive outcomes in fertility-sparing treatment of complex atypical hyperplasia and low-grade endometrial cancer using oral progestin in Chinese patients. Gynecol Oncol. 2015; 139:424-428.

40. Wheeler DT, Bristow RE, Kurman RJ. Histologic alterations in endometrial hyperplasia and well-differentiated carcinoma treated with progestins. Am J Surg Pathol. 2007; 31:988-998.

41. Gonthier C, Walker F, Luton D, Yazbeck C, Madelenat P, Koskas M. Impact of obesity on the results of fertilitysparing management for atypical hyperplasia and grade 1 endometrial cancer. Gynecol Oncol. 2014; 133:33-37.

42. Nardulli AM, Katzenellenbogen BS. Dynamics of estrogen receptor turnover in uterine cells in vitro and in uteri in vivo. Endocrinology. 1986; 119:2038-2046.
43. Lonard DM, Nawaz Z, Smith CL, O'Malley BW. The 26S proteasome is required for estrogen receptor-alpha and coactivator turnover and for efficient estrogen receptoralpha transactivation. Mol Cell. 2000; 5:939-948.

44. Carlson MJ, Thiel KW, Yang S, Leslie KK. Catch it before it kills: progesterone, obesity, and the prevention of endometrial cancer. Discov Med. 2012; 14:215-222.

45. Hotamisligil GS. Inflammation and metabolic disorders. Nature. 2006; 444:860-867.

46. Flegal KM, Carroll MD, Kit BK, Ogden CL. Prevalence of obesity and trends in the distribution of body mass index among US adults, 1999-2010. JAMA. 2012; 307:491-497.

47. Ogden CL, Carroll MD, Kit BK, Flegal KM. Prevalence of obesity and trends in body mass index among US children and adolescents, 1999-2010. JAMA. 2012; 307:483-490.

48. Horn-Ross PL, Canchola AJ, Bernstein L, Deapen D, Lacey JV Jr, Lee E, Nelson DO, Reynolds P. Body size over the life-course and the risk of endometrial cancer: the California Teachers Study. Cancer Causes Control. 2016; 27:1419-1428.

49. Cerami E, Gao J, Dogrusoz U, Gross BE, Sumer SO, Aksoy BA, Jacobsen A, Byrne CJ, Heuer ML, Larsson E, Antipin Y, Reva B, Goldberg AP, et al. The cBio cancer genomics portal: an open platform for exploring multidimensional cancer genomics data. Cancer Discov. 2012; 2:401-404.

50. Gao J, Aksoy BA, Dogrusoz U, Dresdner G, Gross B, Sumer SO, Sun Y, Jacobsen A, Sinha R, Larsson E, Cerami E, Sander C, Schultz N. Integrative analysis of complex cancer genomics and clinical profiles using the cBioPortal. Sci Signal. 2013; 6:pl1.

51. Cancer Genome Atlas. Policies and Guidelines. 2015.

52. R Core Team. R: a language and environment for statistical computing. R Foundation for Statistical Computing, Vienna, Austria. 2014. 